\title{
Sensorimotor modulation and the variable action pattern (VAP): Toward a noncircular definition of drive and motivation
}

\author{
ROY A. WISE \\ Concordia University, Montreal, Quebec, Canada
}

\begin{abstract}
A definition of motivation is proposed which avoids two problems with earlier definitions in the psychological literature. It is nontrivial in that it distinguishes behavior for which a motivational construct is required from behavior that needs no such construct. It is noncircular in that it specifies motivational phenomena by both behavioral and physiological criteria. The modulation of stimulus-response efficacy is suggested as the defining property of motivational states; motivation is seen as altering the strength of, but not substituting for, environmental cues. Hormones and neuromodulators are suggested as the defining components of the mechanisms of motivational states. The fixed action pattern (FAP) of ethologists is designated as the unit of nonmotivated behavior; the variable action pattern (VAP) is designated as the unit of motivated behavior. This view treats hunger and thirst as special cases of motivation, rather than prototypes, and offers a common frame of reference for a wide range of motivations and emotions.
\end{abstract}

\section{EARLY DEFINITIONS OF DRIVE AND MOTIVATION}

Early attempts at behavior theory began with the reflex arc as the basic unit. Behaviorists attempted to characterize acts as composite responses to immediate and specifiable environmental stimuli. As it became evident that responses to the environment were not totally fixed by immediate stimuli, but rather could differ (despite the same stimulus setting) as a function of deprivation states, attentional sets, and prior experience, the stimulusresponse (S-R) formula was modified. The construct of motivation was adopted in various attempts to explain complex (not obviously reflexive) behavior in which the same apparent stimulus did not always elicit the same response.

A major limitation of motivational theory has, from the start, been a failure to find an adequate definition. Troland (1928) realized this problem in his early volume dedicated to the place of motivation in behavior theory: "It may be said that there is no question of motivation in a cough, but that the cigarette habit may require a motivational explanation. However, as we have already pointed out, it is hardly safe to start with a distinction of this sort, since

\footnotetext{
Preparation of this manuscript was supported in part by grants from the Natural Sciences and Engineering Research Council of Canada and the National Institute on Drug Abuse of the United States (DA 01720). I owe much to seminal discussions with, and the hospitality of, Dalbir Bindra and Floyd Bloom; many of these ideas began to take shape in their labs. I also thank George Siggins and Peter Shizgal for their early suggestions and critical comments.

The author's mailing address is: Department of Psychology, Center for Studies in Behavioral Neurobiology, Concordia University, 1455 de Maisonneuve Blvd. West, Montreal, P.Q., Canada H3G IM8.
}

we may eventually discover that the fundamental principles which control reflexes and habits are the same, at least in part" (p. 91). Troland treated motivation with the realization that "as a rule, when we ask for a motive, we are thinking of something mental, rather than purely physiological or physical in nature, in spite of the fact that the effect which has to be explained is the behavior of the organism" (p. 10).

Thus Troland anticipated the major criticism of motivational theory-a criticism that applies equally today. Skinner, for example, has argued that it is counterproductive to attribute behavior to "inner causes" such as motives or drives. He argues, "The practice of looking inside the organism for an explanation of behavior has tended to obscure the variables which are immediately available for a scientific analysis. These variables lie outside the organism, in its immediate environment and in its environmental history"' (Skinner, 1953, p. 31). Skinner has taken particular issue with the concept of drive. "Needs, wants, and hungers," he says, "are good examples of the inner causes [mentioned above].... Needs and wants are likely to be thought of as psychic or mental, while hungers are more likely to be thought of as physiological. But the terms are freely used when nothing with these dimensions has been observed" (Skinner, 1953, p. 143). Skinner's telling point is that such terms are usually circularly defined; motivation is often inferred from the behavior it is intended to explain. Skinner suggests that behavior is adequately analyzed without notions of drive and motivation, since these terms merely cloud the relations between the antecedents of the postulated motivational state and the behavior attributed to that state.

Motivational theory survives despite the harsh criticism by Skinner and others. One or another motivational con- 
struct continues to be deemed necessary by most behavior theorists, and chapters on motivation still appear in most psychology textbooks. A motivational construct is generally deemed necessary because the same environmental stimulus does not always elicit the same behavioral response (Hinde, 1970, pp. 193-202). Even in the sterile environment of the operant chamber, the specifics of behavior are not controlled simply by the immediate environmental stimuli. Animals can be influenced to attend to or ignore a given environmental stimulus by a variety of "motivational" manipulations.

Modern psychological theory has, nonetheless, attempted to divorce itself from notions involving mental causes, and, in so doing, has attempted to link motivational constructs to the environmental history of the animal. Drive theory was most successful in this regard, but even drive theory has not offered an adequate motivational construct. Motivation and drive have generally been categories or labels rather than effective explanatory constructs or intervening variables. Even a simple definition of these terms has been troublesome and has gone through several phases. Drives were once conceived in parallel with instincts, which were not themselves adequately differentiated from reflexes. Each was a term for which satisfactory definition was elusive; rather than abstract principles, lists of specific examples were variously proposed by different authors. In the early view, drives were seen as having stimulus properties; they were seen to differ from reflexes in complexity, but there was no clear distinction from reflexes on qualitative grounds.

With behaviorist attempts to define drives in a noncircular manner, drive came to be modeled largely after hunger, and hunger came to be defined in terms of tissue needs and in units of food deprivation (Cannon, 1932; Hull, 1952; Richter, 1927; Woodworth, 1958). The notion of Bernard (1859, cited in Cannon, 1932, p. 32) that the milieu intérieur must be maintained within narrow limits-a notion captured in Cannon's (1929) term homeostasis-came to influence motivational theory. The notion of "behavioral homeostasis" is the notion that behavior, like simple physiological reflexes, serves to satisfy physiological needs. Much of regulatory physiology continues to study hunger and thirst from this perspective. The notion of specific appetites for salt (Richter, 1947) and other minerals (Milner \& Zucker, 1965; Richter \& Eckert, 1937) fits well with such a view, as does the finding that renin (a substance released by the kidney under conditions of low blood pressure) and its metabolites precipitate not only reflexive renal water conservation but also instrumental, waterseeking behavior (Fitzsimons, 1971).

Within the mainstream of psychological theory, it was Hull (1943) who took this view to the point where its inadequacies became clear. Hull looked to the biology of physiological needs (Cannon, 1932; Richter, 1927) for this definition of motivation. However, all motivation could not be linked to clear biological needs, and need reduction (which was tied to biological factors) and eventually drive reduction (which was not) failed as general explanations of behavior. Need reduction did not, for example, offer a satisfactory explanation of sexual behavior or nest building, for reproduction can, at best, be seen as a need of the species, not a need of the tissue of the individual animal. To suggest that the individual acts to satisfy a need for species survival is to espouse a teleology that is more at home in theology than in biology. To suggest that the need for species survival gives rise to a sex drive and that the drive then explains mating behavior is to indulge in circularity of the sort Skinner (1953) rightly criticized. Attempts to adapt drive theory to the explanation of play and curiosity were even more clearly inadequate (Harlow, 1953). Although the concept of homeostatic need offered a biological-and thus noncircular-definition of hunger and thirst, it did not offer a definition of drive that spanned the significant range of accepted motives.

Drive theory was gradually replaced by activation theory and then incentive theory as the dominant view of motivation. Activation theory attempted, like early drive theory, to link motivation to a physiological mechanism. If this could be done, motivation would stand as a concept tied to empirical events, safe from the criticism of Skinner. Lindsley (1951), Hebb (1955), Magoun (1958), Malmo (1959), Berlyne (1962), Duffy (1962), and others looked to the anatomy of the reticular formation for a distinct biological substrate of motivation. The reticular formation had several properties of interest, but the reticular formation itself turned out to be ill-defined and it lost its appeal as a unitary mechanism for motivation when it was seen that there was not a unitary phenomenon or mechanism of arousal (see, e.g., Vanderwolf \& Robinson, 1981, and the associated commentary).

The current view on motivation-incentive motivational theory-no longer has the details of a postulated physiological correlate. Thus, one of Skinner's suggestionsthat psychologists not concern themselves with physiology-has largely been heeded. Once again, however, motivation lacks a noncircular definition. Modern psychology has forgotten Skinner's other criticism-that mental causes are usually circularly defined. Modern motivational theory does not offer a definition that distinguishes the class of motivated behaviors from any specified class of nonmotivated behaviors. Once again, motivational theorists find it necessary to resort to lists of motivations rather than to an explicit principle of motivation. Once again, drive has been relegated, at least partially, to the domain of stimulus control of behavior (e.g., Bindra, 1978; Bolles, 1972; Harlow, 1953), and, once again, the difference between "drive stimuli" or "incentive motivational stimuli" and "regular" stimuli remains to be identified in nonmentalistic terms.

Can this possibly be a fair assessment of the state of the art? Can motivational theory have flourished (Beck, 1978; Bindra, 1959; Bolles, 1967, 1975; Petri, 1981) without an answer to Skinner's claim of circularity? One need only turn to examples from the literature to illustrate a general lack of adequate motivational definitions. 
One might look first to the textbooks on motivation. If the leading theories of motivation have dealt with the established challenge of Skinner and others, then each motivation textbook should provide an early section that discusses the ways in which a concept of motivation is not merely an escape to the mentalism that Skinner denounced. A quick sampling of recent texts makes the lack of adequate definition clear. Petri $(1981$, p. 3) defines motivation as "the concept we use when we describe the forces acting on or within an organism to initiate and direct behavior." Jones (1955), in introducing the influential Nebraska Symposium on Motivation, defined the problem of motivation as the problem of "how behavior gets started, is energized, is sustained, is directed, is stopped, and what kind of subjective reaction is present in the organism while all this is going on." Littman (1958), a few years later in the same series, made it even more clear that various concepts of motivation include all aspects of behavior and cannot be distinguished, on general principle, from nonmotivational concepts. Beck (1978) devotes a chapter to "the concept of motivation" and a section to "the definition of motivation." However, his italicized definition is as follows: "Motivation is broadly concerned with the contemporary determinants of choice (direction), persistence, and vigor of goaldirected behavior" (p. 24). This definition again fails to indicate what aspects of behavior are nonmotivational. For a definition of motivation to be useful, there must not only be a class of well-distinguished motivational variables; there must also be a well-distinguished class of nonmotivational variables. Beck (1978, p. 25) explains that we cannot "just define motivation; we define a set of variables that are called motivational." Among the variables that he mentions are "desire" and "aversion," which are just the kind of mental causes to which Skinner objected decades ago. No variables are specified as independent of motivation. Three decades ago, Bindra (1959), in lieu of a definition of the term "motivation," said, "Psychology has not yet reached the stage where its subject matter can be divided into well-defined and theoretically meaningful sections. Thus the dividing lines between its currently recognized main areas, such as perception, learning, and motivation, are far from clear. Rather, these areas are identified and distinguished from each other only on the basis of the types of phenomena and theoretical questions that have traditionally been included in them" (p. 3). In Beck's attempt to deal with the problem of definition by listing the variables that are called motivational, it is clear that the problem of definition remains today in the condition described by Bindra in 1959.

Thus, it is argued here that the first problem of motivational theory remains unresolved: the terms "drive" and "motivation" must be adequately defined. For the definition to be adequate, two criteria must be met. First, Skinner's criterion of noncircularity must be met. Motivation cannot, if it is to have any heuristic value or scientific respectability, be defined in terms of "desires" and "aversions" which are inferred from the very behavior the motivational concept is used to explain. Second, it must meet another criterion implied in Skinner's analysis. Skinner presumes that the concept of motivation adds nothing new to principles of behavior that can be developed without a motivational concept. Indeed, if it were the case that all behavior were motivated, then the concept of motivation would be superfluous. The second test of the adequacy of a definition of motivation is that it be useful; to be useful, it must distinguish the class of motivational phenomena from some significant and wellidentified class of nonmotivational phenomena. If all behavior is "motivated," then the concept of motivation is theoretically trivial.

\section{BIOLOGICAL DEFINITIONS OF DRIVE AND MOTIVATION}

One approach to the problem of circularity is to define motivation in biological terms - terms independent of the behavior that the concept is used to explain. The first major attempts by psychologists to anchor the concept of motivation in biology were views that focused on the physiological needs of the body. After the failure of drive theory, activation theory again attempted to link the concept of motivation to a biological mechanism. Lindsley (1951), Hebb (1955), Magoun (1958), Malmo (1959), Berlyne (1962), Duffy (1962), and others offered theories of motivation that were noncircular in that they were tied to physiological events and not just to the behavior they were intended to explain. Hebb, in particular, felt this was essential. Hebb (1955) argued that our conception of brain function necessarily limited our theories about the organization of behavior; he suggested that those who attempted to formulate behavioral theory without explicit consideration of the principles of brain function merely relied on outdated (common sense) views of brain function. Hebb did not offer a physiologically based theory as a solution to Skinner's criticism of circularity, but he argued for a discussion of behavior in terms of the brain that organizes that behavior. So long as physiological mechanisms can be specified, the problem of circularity does not arise, since motivation is not defined solely in terms of the behavior it is intended to explain.

Hebb discussed, in 1955, the importance of a new anatomical distinction-one between (a) the divergent conduction and nonspecific projections of the newly discovered reticular activating system and (b) the parallel conduction and topological organization of the conceptual nervous system of the 1930s and 1940s-for motivational theory. This distinction suggested a basic difference between the nature of information flow in motivational and sensorimotor pathways, and this difference, as discussed by Lindsley (1951), Hebb (1955), Magoun (1958), and others, formed the biological foundation of the arousal theories that dominated the psychol- 
ogy of motivation in the 1950s and 1960s (Berlyne, 1962; Duffy, 1962; Hebb, 1955; Lindsley, 1951; Magoun, 1958; Malmo, 1959).

Just as Hebb offered a simple biological distinctionthe distinction between parallel and divergent conduction-as a distinction of relevance for motivational theory in the 1950 s, so might another, newer, biological distinction be offered to advance motivational theory in the 1980s. The new distinction is the distinction between "neuromodulators" and the classic, idealized neurotransmitter. The principle of modulation is a principle of brain function that seems well suited to the mediation of motivational phenomena and offers a distinction in principle between simple response-eliciting effects of external events, on the one hand, and the effects of motivational and emotional states, whether they be activated by hormones, tissue depletions, or external stimuli, on the other.

\section{DRIVE AND THE CNS: AN UPDATE}

An essential feature of the conceptual nervous system of the 1960s was the widely held view of homogeneity of synaptic communication. The textbook view of synaptic transmission was one of rapid, punctate communication between nerve cells. The synaptic junction was assumed always to have the same $200-\AA$ width and specialized morphology; this was thought necessary for the restriction of the diffusion of synaptic transmitters. The present paper sketches some of the history of this view and summarizes some of the findings that have led to its liberalization; it then points out some implications for motivational theory of the newer conceptual nervous system in which there is a broader range of synaptic structure and function.

\section{Variability of Communication Between Nerve Cells}

Early in this century, Dale $(1935,1937)$ was interested in the biochemical heterogeneity of neurons. Dale argued that the nature of the chemical messenger contained in a neuron would determine a common action at all of its terminals (this has come to be known as "Dale's principle'); at the same time, he anticipated that different classes of neurons, with different chemical messengers, might communicate in a variety of ways and might serve a variety of functions. Eccles $(1936,1937,1946)$ and his co-workers (Brooks \& Eccles, 1947), on the other hand, advanced the view that the chemical events in the synapse were too slow to have functional importance and that it was the electrical synaptic events, common to all neurons regardless of their chemical composition, that were critical for information flow in the nervous system. This view was associated with very narrow assumptions regarding the potential range of synaptic dimensions and the potential time course of synaptic communication (see Eccles, 1957, p. 217). It was Eccles's view, rather than the earlier and more accurate insight of Dale, that dominated the conceptual nervous system of the 1950 s and 1960 s.
One can never know for certain why one view is more influential than another, but it seems likely that the narrow view of acceptable synaptic parameters, which followed from the electrical transmission theory of Eccles, held sway over the more accurate view of Dale-even after the electrical transmission doctrine was disprovenbecause Dale's writings were ahead of their time and because it was Eccles (Brock, Coombs, \& Eccles, 1951, 1952) with his assumptions, and not Dale with his, who eventually demonstrated and described how synaptic transmission depended on the movement of specific chemicals, and not merely the ionic flux, in the synaptic gap.

Whatever the historical causes, the textbook neurotransmitter was standardized with the characteristics of acetylcholine in the nicotinic junction where it had been first studied by Eccles and his collaborators. All synapses were expected to have the membrane specializations and narrow synaptic gap that typified this prototype of neuronal communication (Eccles, 1957), and this expectation soon dominated the literature. Work of the last decade, however, has shown that the time course of neuronal communication and the anatomical sphere of influence of a chemical messenger are not at all standard across various chemical messengers and their neuronal carriers (Bloom, 1979; Dismukes, 1979; Eccles \& McGeer, 1979; Kupfermann, 1979). Because of the dominance of the once-persuasive view that a neurotransmitter had to have a fast action over a narrow synaptic gap (e.g., B. Scharrer, 1969), some workers of the last decade have found it useful to suggest new names for some of the chemical messengers released by neurons to influence postsynaptic information flow (see Dismukes, 1979, and associated commentary). It is important for the behavioral theorist to be aware of these developments because one of the new categories, neuromodulators, has particular importance for motivational theory. It is equally important for basic neuroscientists to be aware of the behavioral data that demand just such a neuronal messenger for motivational function.

\section{Neurohormones, Neuromodulators, and Neurotransmitters}

One of the major tasks of the electrophysiologist has been to determine which of the chemical constituents of the brain have neurotransmitter functions (Werman, 1966). Several criteria have been used: (1) the substance must be shown to be present within the terminals of the neurons in question; (2) it must be released by these neurons when they are stimulated; (3) the purified substance, when applied experimentally to the postsynaptic cell, must produce the same response as does stimulation of the presynaptic fibers; and (4) the effects of nerve stimulation and of experimental application of the pure substance must both be responsive to the same pharmacological manipulations. It is in the application of these criteria that Dale's concern for the chemical individuality of different neurons has recently come to demand full appreciation. Not only do neurons with different transmitters react 
differently to drugs and participate differently in various behavioral functions (as is already well appreciated), but they also communicate by quite different cellular mechanisms and with quite different temporal and spatial characteristics. This realization has gradually emerged as the list of putative neurotransmitters has grown from a few to a dozen (Bloom, 1977; Florey, 1984; Iversen, 1983; Krnjevic, 1974). When only a few substances were established as neurotransmitters, it was difficult to imagine the range of characteristics the model neurotransmitter would have to encompass.

Several deviations from the traditional conception (though perhaps not from the literal definition) of the model neurotransmitter have led to the emergence of two new terms-" "neurohormone" and "neuromodulator." Each has been proposed as reflecting some difference in principle of action from the classically viewed neurotransmitter, and each has been the subject of some controversy regarding semantic heuristics (e.g., Dismukes, 1979, and associated commentary).

The term neurohormone was coined (E. Scharrer \& B. Scharrer, 1963) to denote peptides, such as vasopressin and oxytosin, that are secreted by cells of the paraventricular and supraoptic hypothalamic nuclei. These peptides share with neurotransmitters the fact that they are localized in neurons and are released as a result of cell firing. They are distinguished from neurotransmitters, however, in that they are not released, at least from their presumed projection to the pituitary, into a synaptic junction where they have a localized and rapid action. Rather, they are released into the circulation for distribution like hormones to distant targets; thus they are seen as having slow time courses of action. The nature of the anatomical link between the neuron and its targets was deemed the primary defining difference between neurosecretory cells that release hormones and nerve cells that release transmitters, but recent discoveries have made definitions based on this criterion tenuous. Not all synapses have anatomically tight couplings to their target neurons. It is clearly established in the peripheral nervous system (Cantino \& Mugnaini, 1974), and it is argued for the central nervous system as well (Descarries, Beaudet, \& Watkins, 1975; Descarries, Watkins, \& Lapierre, 1977; Koda \& Bloom, 1977; Pickel, Joh, \& Reis, 1976; Tennyson, Heikkila, Mytilineou, Cote, \& Cohen, 1974), that not all neuronal junctions have the typical narrow synaptic gap with its traditional synaptic membrane thickenings.

Moreover, it is now thought that the neurohormone peptides, released in the pituitary to be carried to distant targets by the circulation, are also released onto neural targets within the brain. The source of the synaptic release of these peptides seems either to be fibers from different cells located in the same nuclei or to be collaterals from the very axons that project also to the pituitary (Nicoll $\&$ Barker, 1971; Swanson, 1977). Thus, the distinction between neurohormone and neurotransmitter is not a clean one; nonetheless, it is one which calls attention to the fact that chemical messengers of the brain can act with a good deal of variability in their anatomical spheres of influence.

The catecholamines, which are thought to be importantly involved in motivational function (Ahlskog \& Hoebel, 1973; Fibiger, 1978; German \& Bowden, 1974; Leibowitz, 1978; Stricker \& Zigmond, 1974; Wise, 1978, 1982), are particularly difficult to categorize along this dimension. They are in some cases released by nonneural elements like the adrenal medulla to act as circulating hormones, yet the same substances are in other cases released by neurons to act like transmitters in the peripheral (Von Euler, 1946) and central (Bloom \& Hoffer, 1973; Bloom, Hoffer, \& Siggins, 1972; Cederbaum \& Aghajanian, 1976; Hökfelt, Fuxe, Goldstein, \& Johansson, 1974) nervous systems. In the peripheral nervous system, they are released from axons that, in some cases, do not have synaptic membrane specializations or make tight synaptic contacts (Cantino \& Mugnaini, 1974). Several authors have suggested that catecholamines may be released from nonspecialized nerve endings to act at relatively unrestricted distances in the CNS as well (Descarries et al., 1975; Pickel et al., 1976; Tennyson et al., 1974). In some cases, however, there are clear membrane specializations and traditional synaptic junctions at central catecholamine terminals (Descarries et al., 1977; Groves, 1980; Groves \& Wilson, 1980; Koda \& Bloom, 1977; Koda, Wise, \& Bloom, 1978); thus catecholamines cannot be safely categorized as either neurotransmitters or neurohormones on the basis of the anatomy of their release sites.

The term neuromodulator has been coined to stress the fact that the chemical messengers of the brain act with a good deal of functional as well as anatomical variability. Eccles once postulated that any given neurotransmitter could have only one of two possible synaptic actionsexcitation or inhibition-and that this action would involve the opening of one and only one form of ionic gate on the postsynaptic membrane (Eccles, 1964). However, a careful analysis of the catecholamine and peptide messengers has shown the lack of generality of this view. The term neuromodulator has been coined for different reasons and is used somewhat differently by different authors (Barchas, Akil, Elliot, Holman, \& Watson, 1978; Barker, 1977; Dismukes, 1979; Kupfermann, 1979), but it generally has been used to denote the catecholamine and peptide messengers that do not seem to have traditional postsynaptic actions; their actions are slow, they are longlived, and they do not appear to have traditional depolarizing or hyperpolarizing effects on postsynaptic membranes. The defining property of the term neuromodulator is that the substance in question is more an amplifier than an instigator of synaptic information flow. Krivoy and his coworkers have used this term to contrast the softer excitatory effects of peptides on spinal neurons against the "detonating" effects of classic excitatory transmitters. They found that substance $\mathbf{P}$ and $\beta$-melanocyte stimulating hormone $(\beta-\mathrm{MSH})$ altered dorsal root evoked potentials and monosynaptic reflexes in the cat spinal cord but 
did not produce spontaneous discharge or reflex activity themselves (Krivoy, 1961; Krivoy \& Guillemin, 1961; Krivoy, Lane, \& Kroeger, 1963). The lack of behavioral effects of these substances led to the suggestion that they modified synaptic activity without eliciting it; in this view, $\beta$-MSH was seen as a possible modulator of "central excitatory state" (Krivoy \& Guillemin, 1961), just as the reticular formation had earlier been seen as serving such a function in the motivational theories of Hebb (1955) and others.

A view similar to Krivoy's was articulated by Barker, Neale, Smith, and MacDonald (1978), who defined neuromodulation as the alteration of synaptic receptor-coupled ionic conductances that are caused by other synaptic messengers without any direct activation of conductance changes as a primary consequence of their own action. This view fits the actions just described for $\beta$-MSH and substance $P$ and also those of the more recently studied peptide thyrotropin releasing hormone (TRH: Nicoll, 1978) as well as those of the opioid peptides discussed by Barker et al. Elliott (1960) and Florey $(1960,1967)$ have used the terms "modulator substance" and "moderator" in a similar way.

It would appear that the catecholamines are also best viewed as neuromodulatory messengers, although they do cause postsynaptic conductance changes, albeit by an indirect mechanism (Bloom, 1975; Greengard, 1976; Nathanson, 1977), at least in some cases (Seeman, 1980). The most straightforward example of a catecholamine modulatory action involves dopamine normally released from interneurons in the superior cervical ganglion: here a brief superfusion of dopamine can cause a long-lasting ( 3 or more hours) and dramatic (doubling) change in sensitivity to cholinergic synaptic excitations without causing any direct synaptic excitation of its own (Libet, Kobayashi, \& Tanaka, 1975; Libet \& Tosaka, 1970). A more complex modulatory interaction between a catecholamine and other synaptic elements is seen in the central noradrenergic synapse. Noradrenaline inhibits postsynaptic spontaneous cell firing (cell firing that occurs in the absence of known excitatory inputs) in those central sites where it appears to make junctional contacts (Bloom et al., 1972; Segal \& Bloom, 1974); however, it inhibits elicited firing to a much lesser degree (Foote, Freedman, \& Oliver, 1975; Freedman, Hoffer, Puro, \& Woodward, 1976; Moises, Woodward, Hoffer, \& Freedman, 1979; Reader, Ferron, Descarries, \& Jasper, 1979; Rogawski \& Aghajanian, 1980a, 1980b; Waterhouse, Moises, \& Woodward, 1980). Thus, although inhibitory in its own right, noradrenaline increases the ratio of elicitedto-nonelicted firing or, in a sense, the signal-to-noise ratio. Here is yet another case of a synaptically released substance that may be more important for the amplification of synaptic communications by other elements than for any direct addition of its own to the temporal or spatial patterning of the synaptic information flow.

The new modulatory chemical mesengers have been found since 1955 . They are localized in neurons and are released as a result of neuronal firing, but they do not fit with the 1955 view of a neurotransmitter. In some cases the substances are not unique to neural tissue, and in some cases they do not cause the alterations in ionic conductivity associated with postsynaptic inhibition or excitation; in all cases, they do not alter postsynaptic neurons as rapidly as does the prototypic neurotransmitter acetylcholine at the nicotinic junction. These new chemical messengers have led to a new appreciation of the variability of cellular communication in the CNS. Bloom (1979) has pointed out that the new appreciation may be more semantic than substantive; the new definitions do not clearly distinguish any well-defined set of substances from the conceptual neurotransmitter as it was first discussed and contrasted against the axonal "conductor" by Sherrington at the turn of the century (e.g., Sherrington, 1906). Bloom and others (see Dismukes, 1979, commentary) suggest that what may be more useful than new terminology is a reliberalization of the view of the acceptable range of synaptic parameters.

Whatever they are eventually called, the chemical messengers of the CNS of the 1980s are a varied lot compared with those of 1955 . It is no longer adequate to simply note the algebraic sign of a synaptic relation in diagramming the conceptual nervous system. In the brain maps of today, the functional organization must be reflected in both the anatomical and the neurochemical elements of a given address. Different chemical markers will ultimately be required to indicate the wide range of parameters of interaction, and those interactions seen as slower, more diffuse, and modulatory in nature should emerge as having special interest for the motivational theorist. For the purposes of motivational theory, a distinction between neuromodulatory messengers and the more traditional neurotransmitters is here argued to have immediate heuristic value despite the considerations brought forward by Bloom (1979) and Dismukes (1979). For the purposes of motivational theory, the arrows between the boxes in flow charts such as those of Bindra (1976, e.g., pp. 188, 196) should now be replaced by symbols that distinguish neurotransmitter-mediated relations from neuromodulator-mediated relations. In the future, further refinements of the conceptual nervous system can be predicted. For example, it now seems likely that chemical messengers pass not only from axon to dendrite but also from dendrite to axon (Hattori, McGeer, \& McGeer, 1979; McGeer, McGeer, \& Innanen, 1979), and it seems quite possible that the dendrites can influence not only incoming messages to themselves but also messages targeted for other neurons. These and more traditional presynaptic communication points (Kandel \& Schwartz, 1982; Llinas, 1984; Zieglgansberger, 1984) provide additional mechanisms for modulatory influence which may well have further importance for psychological theory.

\section{A UNIFYING DEFINITION OF DRIVE AND MOTIVATION}

A drive, emotional, or motivational state is here defined as a state of selective modulation of the effective- 
ness of classes of response-eliciting environmental or proprioceptive stimuli (or their central correlates), mediated by a central mechanism involving hormonal or neuromodulatory elements. The behavioral property suggested to distinguish motivational states is that of modulating the intensity of behavioral responses to appropriate releasing stimuli; the property of other behavioral influences that is not shared by motivational states is the ability to elicit motor commands directly.

It is the thesis of the present paper that a heuristic definition of motivation and a heuristic distinction between it and other behavioral influences parallels the definition of hormones and neuromodulators and the distinction between them and the detonating action of the classic neurotransmitter. A neurotransmitter with a detonator action is a rapidly and locally acting chemical messenger that is well suited for the coding and transmission of precise and detailed information through relatively subtle temporal and spatial patterning of nerve impulses. Such impulse patterns can be trusted with the encoded details of environmental circumstances and motor commands, which they convey with some similarity to the flow of information in a digital computer. These transmission systems are critical for perceptual-motor control; they are the primary information pathways for sensory, perceptual, cognitive, and motor messages, and they are the systems that ultimately determine the temporal and spatial patterning of muscle contractions in the skeletal motor system.

Hormones and neuromodulators act too slowly and too diffusely to serve the same functions with the same precision. Hormonal and neuromodulatory systems are ana$\log$ systems, the output of which is a graded function of their more digital afferents; they can serve to alter the general activation level of widespread subsystems of the nervous system, but they do not act with the same discretion as do the classic detonating neurotransmitters. Moreover, these systems do not have significant direct influences on postsynaptic firing patterns. In the present view, this makes them unsatisfactory for transmission of sensory, perceptual, cognitive, or motor messages, but makes them uniquely suitable for mediating the biasing influence of motivational states. The definition of neuromodulators captures what is here designated as the defining property of motivational and emotional states; the distinction between motivational and nonmotivational events is the distinction between the modulation and the elicitation of action.

\section{Modulation at the Behavioral Level}

At the behavioral level, the notion of modulation is best understood in terms of concrete examples. The simplest example of a motivational influence is the modulation of the spinal reflex by stimulation of the reticular formation, a structure that was central to activation theory. Stimulation of regions of the reticular formation, having no effect of its own on muscles of the leg, can either amplify or suppress the knee-jerk reflex when it is triggered by an appropriate tendon-stretching stimulus (French, 1957).
In this case, the message from the stretched tendon is sensory and involves transmission by a classic neurotransmitter system; the message from the reticular formation, since it does not itself trigger the muscle contraction but rather only modifies its strength, would appear to involve a neuromodulatory system, and is here viewed as a motivational or drive-type influence. Although the use of a drive concept to explain modulation of a spinal reflex might be thought to trivialize the concept of drive, it is important to stress that the proposed definition distinguishes drive on grounds of quality and not on grounds of quantity; more complex instances of motivational control involve the same principle and perhaps involve multiple coordinations of similarly simple reflexes.

For an example of modulation of a behavior more traditionally associated with motivation, hormonal control of aspects of sexual behavior can serve. For example, the lordosis reflex of the female rat is triggered by tactile stimuli applied to the flanks and perineum, but this rarely occurs in rats that have been ovariectomized (Komisaruk \& Diakow, 1973). Lordosis can be more readily elicited in ovariectomized rats if vaginal probing is added to palpation of the flanks (Komisaruk \& Diakow, 1973). This reflex is abolished by spinal section (Kow, Montgomery, \& Pfaff, 1977) and depends primarily on cutaneous rather than visual, olfactory, or auditory senses (Kow \& Pfaff, 1976). Lordosis probability and intensity vary greatly in relation to the estrous cycle in normal females and vary with injection dose of estrogen given as replacement therapy in ovariectomized females (Komisaruk, 1971; Komisaruk \& Diakow, 1973). A lordosis response can even be demonstrated in male rats if they are given rectal probing after estrogen injections, but this response to rectal probing is not seen in the absence of estrogen treatment (Komisaruk, 1971). Here estrogen establishes the motivational or drive state. Estrogen does not itself elicit lordosis; rather, it alters the probability and vigor of reflexive responding to the tactile stimuli that do. Estrogen is, in this sense, a motivational modulator of reflex activity. It is generally not found surprising that a hormone should have only a modulatory influence on behavior; indeed, a modulating effect of hormones on sensory control of behavior offers an excellent model of the drive principle, which is here argued to derive not only from hormonally induced drive states, but also from drive states induced by synaptic release of neuromodulatory transmitters in the CNS.

More complex sequences of "goal-directed" behavior can reflect sequences or complexes of reflexive modulations involving the same basic principle. The mating behavior of the ring dove or canary, for example, is under the joint control of multiple environmental stimuli and internal hormones (Lehrman, 1965; Warren \& Hinde, 1959). The sequence begins in the ring dove with bowing and cooing by the male, which leads to nest selection and nest building. After several days of nest building, the female fixes herself in the nest and lays two eggs. The birds alternate incubating the eggs for 2 weeks; then the 
eggs hatch and the parents feed the young by regurgitation. After 2 weeks of feeding, the parents begin to lose responsiveness to the open beaks and feeding calls of the young, and after another week they stop feeding and begin the courtship ritual again.

This cycle represents a sequence of successive changes in responsiveness to environmental stimuli. Nesting material does not elicit nest building except after courtship, and eggs do not elicit incubation except after nest building. Rather, responsiveness to nesting material, eggs, or the begging of the young is seen to occur only at certain times, and the times correspond to periods of specific hormonal activity. During the appropriate period of the cycle, when relevant hormonal activity has been induced by the earlier stages of the sequence, each of these activities dominates, for its time, the behavior of the birds. The domination of behavior that is exerted by eggs is dependent on progesterone, which is present in increasing concentrations as a result of exposure to the mate and nesting material. Even following progesterone injections, the animals do not sit on an empty nest; thus, progesterone does not itself elicit squatting but, rather, modulates the effectiveness of eggs in eliciting this response. Prolactin, which is secreted during the incubation period but not before it, similarly has the ability to maintain the eggs' ability to elicit incubation, although it does not share with progesterone the ability to control the initiation of the incubation response. The work of Lehrman and his coworkers suggests that participation in courtship induces secretion of hormones that leads to domination of behavior by nesting material. Nest building induces secretion of hormones that leads to egg laying and behavioral domination by the eggs that then elicit incubation; stimulation arising from the incubation of eggs induces secretion of a hormone that induces readiness to feed the young when they hatch. If the appropriate hormone is not present, the birds are unresponsive to nesting material, eggs, or the open mouths of the young.

Thus, the modulation of responsiveness to specific stimuli that is seen in the lordosis response of the rat can also be demonstrated in the entire sequence of the reproductive behavior of birds. Hormonal modulation of responsiveness to stimuli is offered here as a good prototypical model of a motivational influence on behavior and as the probable correlate of subjective mood states.

Sexual behavior has not, however, been the traditional model of motivation; rather, it has been something of a stumbling block for early attempts at motivational theory (Harlow, 1953). Motivational theory has focused on what have been taken to be neurally, rather than hormonally, controlled motivational states, particularly the cases of "homeostatic" motivations of hunger and thirst. Much of the study of the physiological psychology of hunger and thirst has dealt with how the neural signals reflecting tissue needs arise. Much attention has focused on identification of glucoreceptors,' which could transduce the signal for hunger, or osmoreceptors, which could transduce the signal for thirst. Thus, the problem for those attempt- ing a unification of motivational theory using hormonal modulation as their model is to show how neuronally, rather than glandularly, controlled motivational states also depend on the modulation priciple. The example that has been developed in the richest detail is feline predatory attack. Here is a sequence of modulated reflexes that appears in nature as a single flow of apparently motivated and goal-directed behavior and that appears to depend on neuronal rather than hormonal modulation.

Feline predatory responses involve visual tracking and stalking of the prey, pouncing, prey positioning (in relation to the mouth), jaw opening, and forceful and rapid jaw closing (Bandler \& Flynn, 1971; Flynn, Edwards, \& Bandler, 1971; MacDonnell \& Flynn, 1966a, 1966b; Wasman \& Flynn, 1962). Each of these stages can be seen to be under modulated reflexive sensory control. Hypothalamic electrical stimulation serves a motivational role in each; the hypothalamic stimulation potentiates the various reflexive components when they are triggered by appropriate sensory events but does not elicit any of these behavioral components in the absence of the relevant peripheral stimuli (Bandler \& Flynn, 1971; MacDonnell \& Flynn, 1966a, 1966b). As the cat pounces, it makes facial contact with the prey, and the first reflex caused by such contact is a head-turning that serves to bring the prey to the midline of the mouth (MacDonnell \& Flynn, 1966a). When the motivated (stimulated) cat is touched on the cheek, it reflexively turns toward the touch stimulus. Hypothalamic stimulation that activates the motivational substrate for this behavior potentiates the head-turn toward the touch stimulus on the cheek. If motivational stimulation is not given, or if it is given to the inappropriate side of the brain, the animal will not turn toward the touch stimulus; in this unmotivated condition, the cat is more likely to turn away from the touch (M. F. MacDonnell, personal communication, 1982). Here, stimulation is clearly modulatory, causing head-turn in neither direction when given in the absence of cheek touch but determining the effectiveness of cheek touch and the direction of response in relation to cheek touch when it occurs.

A more graded modulatory effect is seen in the next tactile reflex of predation-the jaw opening that is normally triggered when the prey is contacted by the perioral region of the cat's face at the midline. Here hypothalamic stimulation again causes no jaw movement by itself, but modulates the response to appropriate tactile stimulation (MacDonnell \& Flynn, 1966a). The modulation can be seen as a shift to shorter and shorter latencies as stimulation intensities are increased. It can also be seen as an alteration of the size of the sensory receptive field of the reflex; touch more and more distal to the midline becomes effective as stimulation intensity is increased (MacDonnell \& Flynn, 1966a). That stimulation modulates sensory control over these reflexes is clearly demonstrated in animals with sensory denervations. The reflex actions do not occur under stimulation in the absence of tactile stimulation; nor do they occur in the presence of tactile stimulation if the sensory branches of the trigeminal nerve 
are cut (MacDonnell \& Flynn, 1966b). Hypothalamic stimulation similarly potentiates visually guided stalking and lunging that normally serve to bring the prey into tactile contact with the cat (Bandler \& Flynn, 1971) and the jaw-closing reflex that usually serves to kill the prey (MacDonnell \& Flynn, 1966a).

Thus, motivational states induced by electrical stimulation of presumably neuronal substrates in the hypothalamus share the property of those induced by hormonal manipulations of mechanisms involved in sexual behavior; in each case, the motivational states modulate sensory control over motor mechanisms without themselves eliciting direct responses in motor mechanisms. It is proposed here that similar control is involved in homeostatic mechanisms, such as those for feeding and drinking, which have similar motivational substrates in this region of the hypothalamus (Glickman \& Schiff, 1967; Smith, 1972; Wise, 1974). Just as hormones modulate responsiveness to stimuli for sexual and parental behavior, so it is postulated that hunger, by activating a modulatory neuronal mechanism, modulates responsiveness to food (Smith, 1972). Modulation of environmental stimulus effectiveness can be accomplished through either hormonal or neuromodulator mechanisms, and such modulation, involving either type of mechanism, is offered here as the common denominator and defining property of all states requiring a motivational construct for their explanation.

\section{Contrast With Earlier Views}

The present view is consonant with the ethological definition of drive and motivation (Fentress, 1982; Hinde, 1970; Lorenz, 1965; Tinbergen, 1951). It is also consistent with contemporary incentive-motivational theory, which contrasts with older psychological views in two important ways. First, it isolates physiological need and individual and species survival as irrelevant concerns. Concern with homeostatic motivations as models of drive has, in the somewhat distant past, caused preoccupation with teleological considerations of survival value that were difficult to reconcile with the inclusion of such things as play and curiosity drives (Fiske \& Maddi, 1961; Harlow, 1953). In the present view, curiosity, play, and sex drives all qualify as readily as do hunger and thirst as motivational states. Here, the defining property of drives is unrelated to the question of whether needs are satisfied by the behavioral mechanism in question. Indeed, in this view, the hormonal modulation of various acts of courtship and copulation are advanced as more useful models of the general principle of motivation than are the approach and ingestion of food or the avoidance of pain. Thus, in the present view, there is no drive hierarchy in which some items are seen as more truly drives than are others and there is no stipulation that drives must be seen as serving some obvious physiological or species need.

The separation of drive and motivation concepts from the notion of homeostasis and from the function of servicing bodily needs does not distinguish the present view from modern views in the field of experimental psychology, but does distinguish it from modern views in other disciplines. Much of regulatory physiology (Epstein, 1973; Friedman \& Stricker, 1976; Kennedy, 1952; Mayer, 1955; Powley \& Keesey, 1970) has viewed motivational states such as hunger and thirst as serving homeostatic needs and as being extensions of the physiological mechanisms that serve to maintain various internal states of the organism in regulatory balance. That hunger and thirst, and the behaviors they potentiate, do influence homeostatic balances cannot be disputed, but the notion that all motivational states must relate to such balances or derive from tissue needs is a notion that has not proven viable in motivational theory. Indeed, some students of regulatory physiology have stressed the need to view so-called "regulatory" behaviors as occurring in anticipation of, and not in response to, bodily needs (Fitzsimons, 1971; LeMagnen, 1971; Toates, 1979). However, the biology of ingestive behavior is still, in the main, overly influenced by the notion that such behavior represents a behavioral mechanism of bodily homeostasis (Cannon, 1932).

Another area in which modern theory still treats motivational states as serving bodily needs is that of addiction theory. Many authors have treated drug-seeking behavior as a case of acquired homeostatic need or hunger (Collier, 1968; Dole \& Nyswander, 1967; Hebb, 1949; Himmelsbach, 1943; Malmo, 1975; Martin, 1968; Wikler, 1952). The present view suggests perspectives (described below) on ingestive and drug-seeking behaviors that incorporate recent psychological advances in motivational theory and model both behaviors on nonregulatory, rather than regulatory, examples of motivation.

The second difference between the present view and earlier views has to do with the nature of the initiation of the motivated act. In nonspecialist views, hunger is seen as the initiator or elicitor of food-seeking and withdrawal symptoms are seen as the elicitor of drug-seeking. Hunger is attributed with stimulus properties and is viewed as a force that drives not only with appropriate intensity but also with appropriate direction. In the present view, and in view of other recent motivational theorists, the elicitation of action is seen as the exclusive domain of environmental stimuli, and only the intensity of responsiveness to such stimuli is seen as being within the domain of motivation (Bindra, 1976; Bolles, 1972; Hinde, 1970; Toates, 1981); on this point, the present view is consistent with the earlier views of Hull (1952) and Hebb (1949).

In the present view, motivated behavior is elicited by the pull of releasing stimuli in the environment and is not driven by the push of drive "stimuli" from within the body. The state of hunger cannot serve as the instigator of a right or a left turn in a maze, for example, since information about the internal state is inadequate for, and in fact irrelevant to, the determination of which of these responses will lead to food. Only information from the external world can identify the left or right turn as being food-associated (although information from memory may 
be required to interpret the sensory cues), since only information from the environment can tell the animal whether it is facing the same direction as in previous trials when a left or a right turn was successful. The role of hunger is to potentiate the effectiveness of food-related environmental stimuli such that their calls for approach responses become more strongly heard, rather than to drive the animal to activity without pause to determine the proper direction for that activity. In this sense, the term "drive" is unfortunate, for it carries the clear connotation of force with direction. "Motivational state" or "central motive state" would be better in this regard, although attempts to use these phrases (Bindra, 1976; C. T. Morgan, 1943) have not lessened the use of the more established term "drive." If drives do not give direction to behavior and do not instigate motor activity themselves, how does one explain the fact that action seems to be elicited and directed only in the appropriate drive state? It should be pointed out from the start that action only seems to be drive-appropriate; even without considering the case of "displacement" activities, behaviors can often be instigated in the absence of the appropriate drive state (Mendelson, 1966; M. J. Morgan, 1974). The initiation of action and its motivational modulation are perhaps best illustrated within the ethological concept of the fixed action pattern (FAP). A FAP is a pattern of behavior that is fixed in the relations of its several component acts to one another (Moltz, 1965). It is a series of reflexive components that, once triggered, runs off with relative invariance, even when there are abrupt environmental changes that make the behavior no longer appropriate. The environmental stimulus that triggers such a pattern is termed a "releasing stimulus" or "releaser," and generally it is quite a narrow range of sensory parameters that defines a releaser for a given FAP. The FAP is seen as being elicited by the releasing stimulus, and not as a simple consequence of the buildup of a drive, except in extreme cases, where the behavior is termed "in vacuo" activity since it occurs in the apparent absence of the appropriate environmental trigger. An example of "in vacuo" activity would be a courtship dance in the absence of a potential mate; "in vacuo" activity is particularly apt to occur in conflict situations (Molz, 1965) or when some fragmentary elements of an appropriate stimulus are present (Lorenz, 1981, pp. 124, 127-129).

So-called "fixed" action patterns are relatively invariant in intensity, however, only when the patterns tend to serve as signals for behavioral responses from conspecifics (Morris, 1957). More typically, action patterns-even FAPs (Schleidt, 1974) - can vary in their intensity or probability of occurrence. Such variability is here posited to result from motivational modulation of the synaptic communication between the sensory neurons activated by the releasing stimulus and the motor neurons controlling the specific muscle excitations that accomplish the response. In the view offered here, a buildup of motivational activation would not trigger "in vacuo" ac- tivity itself, but could at best sensitize the sensorimotor pathway such that some perceptual fragment of the natural releasing stimulus might become effective. To the degree that "in vacuo" activity can be demonstrated reliably and robustly in situations in which there truly is no approximation of an appropriate releasing stimulus in the environment, and to the degree that such activity, in such situations, can be shown to increase in proportion to motivational manipulations such as food deprivation or hormonal injections, the view offered here is inadequate. Lorenz has observed, however, that "it is impossible to say that in vacuo activity occurs 'without any stimulation' because, as in the case of Craig's ring dove which directed its courtship behavior at the meeting point of three straight lines, a substitute object [stimulus] is easy to find, even if it is an extremely weak one' (Lorenz, 1981, p. 127). The view offered here is that a motivational activation cannot, by definition, result in the triggering of action in the absence of some relevant sensory input or its central correlate (the hallucinated stimulus event inferred by Lorenz, 1981, p. 128).

The action patterns that are of greater interest to the psychologist and that are more central to the present attempt to sketch a general view of the nature of motivation are the more variable action patterns that are typical of higher animal species. The present view would stress the ethological concept of the releasing stimulus as useful even here, however, where the readily identified response of a FAP is not necessarily present and where the readily identified and simple features of a releasing stimulus are not so clear. Still, the notion that each component of behavioral responses involving adjustments in space has a sensory input and that it is that input-input from what are still usefully termed "releasing stimuli"which elicits or triggers action is a notion central to the present view (see also Bindra, 1978; Toates, 1981). The sensory input should be the guiding (directing) influence, transmitted to motor centers by classic detonating neurotransmitters; and although the act need not be guided only by environmental stimuli (even in the case of FAPs, muscle feedback forms much of the sensory component of the sensorimotor relation), the act should always be initiated by the environmental releasing stimulus. The term variable action pattern (VAP) will here be used to designate behavioral sequences that differ from FAPs in that they, or some of their components, are modulated in intensity by motivational variables. The VAP is offered as the basic unit of motivated behavior, and the variations in these action patterns are offered as the reflection of the motivational factor. This designation can, in retrospect, be seen to apply to many behaviors that have traditionally been designated as FAPs by ethologists (see Schleidt, 1974).

In the case of feeding, the present view holds that it is food and food-associated stimuli in the environment that call for approach and ingestion responses. Indeed, simple tendencies to approach and withdraw are currently seen as major elements of complex behavioral control (Bindra, 1976) that are modulated by motivational 
mechanisms. It is the relative tendency to approach each of the various stimulus elements in the environment that is seen as responsible for the direction of movement in space; the influence of hunger is not to direct movement itself but, rather, to cause an increase in-a modulation of-the ability of food-associated stimuli to compete with other environmental stimuli which are concurrently calling for approach responses in competition with food. It is the hunger-modulated responsiveness to food-related stimuli that is offered as an explanation of how a hungry animal appears to seek out food preferentially. Food and food-associated stimuli attract considerable attention even from sated animals (particularly humans), and such tendencies may need only slight encouragement in order to make them strong enough to compete successfully with other attractions and to cause initiation of a meal. However, hunger is seen to provide its major control over eating less by facilitating the ability of food to initiate feeding than by modulating the ability of food to sustain feeding and dominate behavior once a meal has been initiated. Hunger makes a meal of what would otherwise be merely a snack or a tasting.

Support for such a counterintuitive view of the major role of hunger can be found in several studies. It is quite clear that even food-related leverpressing or alley-running habits are reliably elicited by environmental stimuli, and can be so elicited even in the absence of an appropriate motivational state (M. J. Morgan, 1974). Animals tested for the first time under conditions of satiety (absence of deprivation) run or leverpress with normal latencies and normal speeds at the beginning of the session (Mendelson, 1966; M. J. Morgan, 1974). It is only after feedback from the earned food pellets is received that the animals begin to slow and finally cease to respond in their habitual way. Thus, in the absence of hunger, responding will not be sustained, although it may well be readily initiated (Wise \& Raptis, 1985). This is in keeping with the present view; hunger does not so much tell us when to eat as determine how rewarding food will be once we happen to taste it. Even in the sated animal, food elicits ingestion and food-associated stimuli elicit approach, but the effectiveness of these stimuli is sufficient to sustain the relevant habits only if the animal is hungry (Mendelson, 1966; M. J. Morgan, 1974). Once initiated in the nonhungry animal, eating and related habits drop out quickly in the same pattern as do nonrewarded habits in extinction testing (M. J. Morgan, 1974); thus it would appear that the critical impact of hunger is to make food sufficiently rewarding to sustain feeding and maintain selective attention once food contact has been made. The subjective reports of humans fit well with the view that hunger modulates the effectiveness of tastes and smells as rewards (Cabanac, 1971). What is counterintuitive is the suggestion that hunger is not a stimulus that prompts food-related action, but rather is merely a state that makes us pay more attention to the readily available food cues that are present in our environment and constantly calling for some degree of attention.
A parallel case can be made in relation to addiction. Just as food is an incentive that attracts the hungry animal, so is a drug an incentive that attracts an addict. Just as tasty substances that do not alleviate tissue needs can serve as incentives for hungry animals (Sheffield \& Roby, 1950) and cool stimuli that do not alleviate tissue needs can serve as incentives for thirsty ones (Mendelson \& Chillag, 1970), so can drugs that do not alleviate withdrawal distress serve as powerful incentives in addicted and even in nonaddicted animals (Bozarth \& Wise, 1983, 1984).

\section{SUMMARY}

The conceptual nervous system (our general assumptions about the limits of brain function) guides and constrains behavioral theories, although not always explicitly. Consideration of recent distinctions between neurotransmitters, neurohormones, and neuromodulators suggests a distinction for psychological theory that allows a definition of motivation based on neurophysiological principle rather than behavioral tautology. Motivation is seen as the variable that translates the fixed action patterns of classical ethology into the variable action patterns of interest to psychologists. Motivation is defined as a state in which sensorimotor relations, or, alternatively, the potency of releasing stimuli, are selectively modulated through hormonal or neural mechanisms that cannot cause motor activity themselves but can alter the effectiveness of other inputs that do cause such activity. With the defining variable being the mechanism of behavioral control and not the consequences of behavioral action or the needs that behavior gratifies, sex, play, and curiosity drives are seen on equal footing with hunger and thirst drives. Hormonal modulation of courtship and mating is offered as the prototypical motivational phenomenon. Modulation of feeding and other "homeostatic" activities is seen to operate on the same principle but to use modulatory neuronal rather than hormonal mechanisms. In this view, hunger is seen as modulating the degree of attention attracted by food and food-related stimuli but not as directing action through any more direct force of its own. It is hoped that this view can bring to the neuroscientist a modern perspective on motivational theory, unifying a concept that was once fragmented by earlier concerns related to the notion that drive must serve biological need, and that it can bring to the behavioral theorist an awareness of contemporary principles of neuronal communication that have implications for the understanding of the biological mechanisms of motivational states.

\section{REFERENCES}

Ahlskog, J. E. , \& Hoebe L, B. G. (1973). Overeating and obesity from damage to a noradrenergic system in the brain. Science, 182, 166-169.

BANDLER, R. J., \& FLYNN, J. P. (1971). Visual patterned reflex present during hypothalamically elicited attack. Science, 171, 817-818.

Barchas, J. D., Akil, H., Eluot, G. R., Holman, R. B., \& WatSON, S. J. (1978). Behavioral neurochemistry: Neuroregulators and behavioral states. Science, 200, 964-973. 
BArker, J. L. (1977). Physiological roles of peptides in the nervous system. In H. Gainer (Ed.), Peptides in neurobiology (pp. 195-243). New York: Plenum Press.

Barker, J. L., Neale, J. H., Smith, T. G., \& MacDonald, R. L. (1978). Opiate peptide modulation of amino acid responses suggests novel form of neuronal communication. Science, 199, 1451-1453.

Basbaum, A. I., \& Fields, H. L. (1978). Endogenous pain control mechanisms: Review and hypothesis. Annals of Neurology, 4, 451-462.

BECK, R. C. (1978). Motivation theories and principles. New York: Prentice-Hall

BERLYNe, D. E. (1962). Conflict, arousal, and curiosity. New York: McGraw-Hill.

BINDRA, D. (1959). Motivation, a systematic reinterpretation. New York: Ronald Press.

BINDRA, D. (1974). A motivational view of learning, performance, and behavior modification. Psychological Review, 81, 199-213.

BINDRA, D. (1976). A theory of intelligent behavior. New York: Wiley.

BinDRA, D. (1978). How adaptive behavior is produced: A perceptualmotivational alternative to response-reinforcement. Behavioral \& Brain Sciences, 1, 41-91.

BLOOM, F. E. (1975). The role of cyclic nucleotides in central synaptic function. Reviews of Physiology Biochemistry \& Pharmacology, 74, 1-103.

BLoom, F. E. (1977). Peptide transmitters: Clues to the chemical cryptogram of inter-neuronal communication? BioSystems, 8, 179-183.

BLoom, F. E. (1979). Contrasting principles of synaptic physiology: Peptidergic and non-peptidergic neurons. In K. Fuxe, T. Hokfelt, \& R. Luft (Eds.), Central regulation of the endocrine system (pp. 173187). New York: Plenum Press.

BLoom, F. E., Hofrer, B. J. (1973). Norepinephrine as a central synaptic transmitter. In E. Usdin \& S. H. Snyder (Eds.), Frontiers in catecholamine research (pp. 637-642). New York: Pergamon Press.

BLOOM, F. E., HofFER, B. J., \& SigGINS, G. R. (1972). Norepinephrine mediated cerebellar responses: A model system for neuropsychopharmacology. Biological Psychiatry, 4, 157-177.

Bolles, R. C. (1967). Theory of motivation. New York: Harper \& Row.

Bolles, R. C. (1972). Reinforcement, expectancy, and learning. Psychological Review, 79, 394-409.

Bolles, R. C. (1975). Theory of motivation (2nd ed.). New York: Harper \& Row.

BozarTh, M. A., \& WiSe, R. A. (1983). Dissociation of the rewarding and physical dependence producing properties of morphine. In L. Harris (Ed.), Problems of drug dependence 1982 (pp. 171-177). Washington: National Institute of Drug Abuse.

BozarTh, M. A., \& Wise, R. A. (1984). Anatomically distinct opiate receptor fields mediate reward and physical dependence. Science, 224, 85-89.

Brock, L. G., CoOmbs, J. S., \& Eccles, J. C. (1951). Action potentials of motoneurones with intracellular electrode. Proceedings of the University of Otago Medical School, 29, 14-15.

Brock, L. G., CoOmBs, J. S., \& ECCLES, J. C. (1952). The nature of the monosynaptic excitatory and inhibitory processes in the spinal cord. Proceedings of the Royal Society (B), 140, 170-176.

Brooks, C., Eccles, J. C. (1947). An electrical hypothesis of central inhibition. Nature, 159, 760-764.

Cabanac, M. (1971). Physiological role of pleasure. Science, 173, 1103-1107.

Cannon, W. B. (1929). Organization for physiological homeostasis Physiological Reviews, 9, 399-431.

Cannon, W. B. (1932). The wisdom of the body. New York: Norton. Cantrino, D., \&ugnaini, E. (1974). Adrenergic innervation of the parasympathetic ciliary ganglion in the chick. Science, 185, 279-281.

Cederbaum, J. M., \& Aghajanian, G. K. (1976). Noradrenergic neurons of the locus coeruleus: Inhibition by epinephrine and activation by the $\beta$-agonist piperoxane. Brain Research, 112, 413-419.

Collier, H. O. J. (1968). Supersensitivity and dependence. Nature. 220, 228-231.

Dale, H. H. (1935). Pharmacology and nerve endings. Proceedings of the Royal Society of Medicine, 28, 319-332.

DALE, H. H. (1937). Transmission of nervous effects by acetylcholine. Harvey Lectures, 32, 229-245.

Descarries, L., Beaudet, A., \& Watkins, K. C. (1975). Serotonin nerve terminals in adult rat neocortex. Brain Research, 100, 563-588 DESCARRIES, L., WATKTNS, K. C., \& LAPIERRE, Y. (1977). Noradrenergic axon terminals in the cerebral cortex of rat. III. Topometric ultrastructural analysis. Brain Research, 133, 197-222.

DismUKes, R. K. (1979). New concepts of molecular communication among neurons. Behavioral \& Brain Sciences, 2, 409-448.

Dole, V. P., \& Nyswander, M. E. (1967). Addiction-A metabolic disease. Archives of Internal Medicine, 120, 19-24.

DuFFy, E. (1962). Activation and behavior. New York: Wiley.

ECCLES, J. C. (1936). Synaptic and neuromuscular transmission. Ergebnisse der Physiologie, Biologischen Chemie und Experimentellen Pharmakologie, 38, 339-444.

ECCLES, J. C. (1937). Synaptic and neuromuscular transmission. Physiological Reviews, 17, 538-555.

ECCLES, J. C. (1946). An electrical hypothesis of synaptic and neuromuscular transmission. Annals of the New York Academy of Sciences, 47, 429-455.

EcCLEs, J. C. (1957). The physiology of nerve cells. Baltimore: Johns Hopkins Press.

EocLes, J. C. (1964). The physiology of synapses. New York: Springer.

ECCLES, J. C., \& MCGeER, P. L. (1979). Ionotropic and metabotropic neurotransmission. Trends in Neuroscience, 2, 39-40.

Elliott, K. A. C. (1960). Concluding statement. In E. Roberts, C. F. Baxter, A. Van Harreveld, C. A. G. Wiersma, W. R. Adey, \& K. F. Killam (Eds.), Inhibition in the nervous system and gammaaminobutyric acid (pp. 260-266). New York: Pergamon Press.

EPSTEIN, A. N. (1973). Epilogue: Retrospect and prognosis. In A. N. Epstein, H. R. Kissileff, \& E. Stellar (Eds.), The neuropsychology of thirst: New findings and advances in concepts (pp. 315-332). Washington: Winston.

FENTRESs, J. C. (1982). Ethological models of hierarchy and patterning of species specific behavior. In E. Satinoff \& P. Teitelbaum (Eds.), Handbook of behavioral neurobiology (Vol. 6, pp. 185-234). New York: Plenum Press.

FIBIGER, H. C. (1978). Drugs and reinforcement mechanisms: A critical review of the catecholamine theory. Annual Review of Pharmacology \& Toxicology, 18, 37-56.

FISKE, D. W., \& MADDI, S. R. (1961). Functions of varied experience. Homewood, IL: Dorsey.

Fitzsimons, J. T. (1971). The physiology of thirst: A review of the extraneuronal aspects of the mechanisms of drinking. In E. Stellar \& J. M. Sprague (Eds.), Progress in physiological psychology (Vol. 4, pp. 119-201). New York: Academic Press.

FLOREY, E. (1960). Physiological evidence for naturally occurring inhibitory substances. In E. Roberts, C. F. Baxter, A. Van Harreveld, C. A. G. Wiersma, W. R. Adey, \& K. F. Killam (Eds.), Inhibition in the nervous system and gamma-aminobutyric acid (pp. 72-84). New York: Pergamon Press.

FLOREY, E. (1967). Neurotransmitters and modulators in the animal kingdom. Federation Proceedings, 26, 1164-1178.

Florey, E. (1984). Synaptic and nonsynaptic transmission: A historical perspective. Neurochemical Research, 9, 413-427.

FlynN, J. P., Edwards, S. B., \& Bandler, R. J. (1971). Changes in sensory and motor systems during centrally elicited attack. $B e$ havioral Science, 16, 1-19.

Foote, S. L., Freedman, R., \& OLIver, A. P. (1975). Effects of putative neurotransmitters on neuronal activity in monkey auditory cortex. Brain Research, 86, 229-242.

Freedman, R., Hoffer, B. J., Puro, D., \& Woodward, D. J. (1976). Noradrenaline modulation of the responses of the cerebellar Purkinje cell to afferent synaptic activity. British Journal of Pharmacology, 57, 603-605.

FrenCH, J. D. (1957). The reticular formation. Scientific American, 196, 54-60.

Friedman, M. I., \& STRICKER, E. M. (1976). The physiological psychology of hunger: A physiological perspective. Psychological Review, 83, 409-431.

German, D. C., \& Bowden, D. M. (1974). Catecholamine systems as the neural substrate for intracranial self-stimulation: A hypothesis. Brain Research, 73, 381-419.

Guickman, S. E., \& SCHIFF, B. B. (1967). A biological theory of reinforcement. Psychological Review, 74, 81-109. 
Greengard, P. (1976). Possible role for cyclic nucleotides and phosphorylated membrane proteins in postsynaptic actions of neurotransmitters. Nature, 160, 101-108.

Groves, P. M. (1980). Synaptic endings and their postsynaptic targets in neostriatum: Synaptic specializations revealed from analysis of serial sections. Proceedings of the National Academy of Sciences (USA), 77, 6926-6929.

Groves, P. M., \& WiLson, C. J. (1980). Fine structure of rat locus coeruleus. Journal of Comparative Neurology, 193, 841-852.

Harlow, H. F. (1953). Mice, monkeys, men and motives. Psychological Review, 60, 23-32.

Hattori, T., McGeer, P. L., \& McGeer, E. G. (1979). Dendro axonic neurotransmission: ПI. Morphological sites for the synthesis, binding and release of neurotransmitters in dopaminergic dendrites in the substantia nigra and cholinergic dendrites in the neostriatum. Brain Research, 170, 71-83.

Heв8, D. O. (1949). The organization of behavior. New York: Wiley.

Hebs, D. O. (1955). Drives and the CNS (conceptual nervous system). Psychological Review, 62, 243-254.

HimmelsbaCH, C. K. (1943). Morphine, with reference to physical dependence. Federation Proceedings, 2, 201-203.

Hinde, R. A. (1970). Animal behavior (2nd ed.). New York: McGraw-Hill.

HöKFelt, T., FuXe, K., Goldstein, M., \& Johansson, O. (1974). Immunohistochemical evidence for the existence of adrenaline neurons in the rat brain. Brain Research, 66, 235-251.

Hull, C. L. (1943). Principles of behavior. New York: Appleton.

Hull, C. L. (1952). A behavior system. New Haven, CT: Yale University Press.

IVERSEN, L. L. (1983). Nonopioid neuropeptides in mammalian CNS. Annual Review of Pharmacology \& Toxicology, 23, 1-27.

JoNEs, M. R. (1955). Introduction. In M. R. Jones (Ed.), Nebraska Symposium on Motivation (p. vii). Lincoln: University of Nebraska Press.

KANDEL, E. R., \& SCHWARTZ, J. H. (1982). Molecular biology of learning: Modulation of transmitter release. Science, 218, 433-443.

KenNedy, G. C. (1952). The role of depot fat in the hypothalamic control of food intake in the rat. Proceedings of the Royal Society $(B), 140$, 578-592.

KoDA, L. Y., \& BLOоM, F. E. (1977). A light and electron microscopic study of nor-adrenergic terminals in the rat dentate gyrus. Brain Research, 120, 327-335.

KodA, L. Y., Wise, R. A. , BLoom, F. E. (1978). Light and electron microscopic changes in the rat dentate gyrus after lesions or stimulation of the ascending locus coeruleus pathway. Brain Research, 144, 363-368.

KoMISARUK, B. R. (1971). Induction of lordosis in ovariectomized rats by stimulation of the vaginal cervix: Hormonal and neural interrelationships. In C. H. Sawyer \& R. A. Gorski (Eds.), Steroid hormones and brain function (pp. 127-135). Berkeley: University of California Press.

Komisaruk, B. R., Diakow, C. (1973). Lordosis reflex in rats in relation to the estrous cycle, ovariectomy, estrogen administration and mating behavior. Endocrinology, 93, 548-557.

Kow, L., Montgomery, M. D., \& Pfaff, D. W. (1977). Effects of spinal cord transactions on lordosis reflex in female rats. Brain Research, 123, 75-88.

Kow, L., \& PFAFF, D. W. (1976). Sensory requirements for the lordosis reflex in female rats. Brain Research, 101, 47-66.

KrIvoY, W. A. (1961). A comparison of the action of substance P and other naturally occurring polypeptides on spinal cord. Proceedings of the Scientific Society of Bosnia and Herzegovina-Yugoslavia, 1, 131-137.

KRIVoY, W. A., \& Gullemin, R. (1961). On a possible role of $\beta$ melanocyte stimulating hormone ( $\beta$-MSG) in the spinal cord of the cat. Endocrinology, 69, 170-175.

Krivoy, W. A., LANE, M., \& Kroeger, D. C. (1963). The actions of certain polypeptides on synaptic transmission. Annals of the New York Academy of Sciences, 104, 312-329.

KRNJEVIC, K. (1974). Chemical nature of synaptic transmission in vertebrates. Physiological Reviews, 54, 418-540.
KupfermanN, I. (1979). Modulatory actions of neurotransmitters. Annual Review of Neuroscience, 2, 447-465.

LEHRMAN, D. (1965). Interacton between internal and external environments in the regulation of the reproductive cycle of the ring dove. In F. A. Beach (Ed.), Sex and behavior (pp. 355-380). New York: Wiley.

LEIBOWITZ, S. F. (1978). Paraventricular nucleus: A primary site mediating adrenergic stimulation of feeding and drinking. Pharmacology Biochemistry \& Behavior, 8, 163-175.

LEMAGNEN, J. (1971). Advances in studies on the physiological control and regulation of food intake. In E. Stellar \& J.M. Sprague (Eds.), Progress in physiological psychology (Vol. 4, pp. 203-261). New York: Academic Press.

Libet, B., Kobayashi, H., \& TaNaKa, T. (1975). Synaptic coupling into the production and storage of a neuronal memory trace. Nature, 258, 155-157.

LIBET, B., \& ToSAKA, T. (1970). Dopamine as a synaptic transmitter and modulator in sympathetic ganglia: A different mode of synaptic action. Proceedings of the National Academy of Sciences (USA), 67, 667-673.

LiNDSLEY, D. B. (1951). Emotion. In S. S. Stevens (Ed.), Handbook of experimental psychology (pp. 473-515). New York: Wiley.

LitTman, R. A. (1958). Motives, history, and causes. In M. R. Jones (Ed.), Nebraska Symposium on Motivation (pp. 114-168). Lincoln: University of Nebraska Press.

LunNas, R. R. (1984). The squid giant synapse. Current Topics in Membranes \& Transport, 22, 519-546.

LORENZ, K. Z. (1965). Evolution and modification of behavior. Chicago: University of Chicago Press.

LORENZ, K. (1981). The foundations of ethology. New York: Springer.

MacDonnell, M. F., \& FLYNN, J. P. (1966a). Control of sensory fields by stimulation of hypothalamus. Science, 152, 1046-1048.

MacDonnell, M. F., \& FlynN, J. P. (1966b). Sensory control of hypothalamic attack. Animal Behaviour, 14, 399-405.

Magoun, H. W. (1958). The waking brain. Springfield,IL: Thomas.

Malmo, R. B. (1959). Activation: A neuropsychological dimension. Psychological Review, 66, 367-386.

MALMo, R. B. (1975). On emotions, needs, and our archaic brain. New York: Holt, Rinehart \& Winston.

MarTin, W. R. (1968). A homeostatic and redundancy theory of tolerance and dependence to narcotic analgesics. Research Publications of the Association for Research on Nervous \& Mental Disorders, 46, 206-225.

MAYER, J. (1955). Regulation of energy intake and the body weight: The glucostatic theory and the lipostatic hypothesis. Annals of the New York Academy of Science, 63, 15-43.

McGeer, P. L., McGeer, E. G., \& Innanen, V. T. (1979). Dendroaxonic transmission: I. Evidence from receptor binding of dopaminergic and cholinergic agents. Brain Research, 169, 433-441.

MENDELSON, J. (1966). The role of hunger in T-maze learning for food by rats. Journal of Comparative \& Physiological Psychology, 62, 341-349.

Mendelson, J., \& Chillag, D. (1970). Tongue cooling: A new reward for thirsty rodents. Science, 170, 1418-1421.

Milner, P. M., \&uCKer, I. (1965). Specific hunger for potassium in the rat. Psychonomic Science, 2, 17-18.

Moises, H. C., Woodward, D. J., Hoffer, B. J., Freedman, R. (1979). Interactions of norepinephrine with Purkinje cell responses to putative amino acid neurotransmitters applied by microiontophoresis. Experimental Neurology, 64, 493-515.

MolTz, H. (1965). Contemporary instinct theory and the fixed action pattern. Psychological Review, 70, 123-138.

Morgan, C. T. (1943). Physiological psychology. New York: McGraw-Hill.

MoRgan, M. J. (1974). Resistance to satiation. Animal Behaviour, 22 , 449-466.

MoRRs, D. (1957). "Typical intensity" and its relation to the problem of ritualization. Behaviour, 11, 1-12.

Nathanson, J. A. (1977). Cyclic nucleotides and nervous system functions. Physiological Reviews, 57, 157-256.

Nicoll, R. A. (1978). Physiological studies on amino acids and pep- 
tides as prospective transmitters in the CNS. In M. A. Lipton, A. DiMascio, \& K. F. Killam (Eds.), Psychopharmacology: A generation of progress (pp. 103-118). New York: Raven Press.

NICOLL, R. A., \& BARKER, J. L. (1971). The pharmacology of recurrent inhibition in the supraoptic neurosecretory system. Brain Research, 35, 501-511.

PETRI, H. L. (1981). Motivation theory and research. Belmont, CA: Wadsworth.

Pickel, V. M., JoH, T. H., \& ReIS, D. J. (1976). Monoaminesynthesizing enzymes in central dopaminergic, noradrenergic and serotonergic neurons. Immunocytochemical localization by light and electron microscopy. Journal of Histochemistry \& Cytochemistry, 24, 792-806.

POWLEY, T. L. , \& KEESEY, R. E. (1970). Relationship of body weight to the lateral hypothalamic feeding syndrome. Joumal of Comparative \& Physiological Psychology, 70, 25-36.

READER, T. A., FERron, A., DescarRIES, L., JASPER, H. L. (1979). Modulatory role for biogenic amines in the cerebral cortex. Microiontophoretic studies. Brain Research, 160, 217-229.

RICHTER, C. P. (1927). Animal behavior and internal drives. Quarterly Review of Biology, 2, 307-343.

RiCHTER, C. P. (1947). Biology of drives. Journal of Comparative \& Physiological Psychology, 40, 129-134.

RICHTER, C. P., \& ECKERT, J. F. (1937). Increased calcium appetite of parathyroidectomized rats. Endocrinology, 21, 50-54.

RogaWsKI, M. A., \& AGHAjanian, G. K. (1980a). Modulation of lateral geniculate neurone excitability by noradrenaline microiontophoresis or locus coeruleus stimulation. Nature, 287, 731-734.

Rogawski, M. A., \& Aghajanian, G. K. (1980b). Norepinephrine and serotonin: Opposite effects on the activity of lateral geniculate neurons evoked by optic pathway stimulation. Experimental Neurology, 69, 678-694.

SCHARRER, B. (1969). Neurohumors and neurohormones: Definitions and terminology. Journal of Neurovisceral Relations, Suppl. IX, 1-9.

SCHARRER, E., \& SCHARRER, B. (1963). Neuroendocrinology. New York: Columbia University Press.

SCHLEIDT, W. M. (1974). How "fixed" is the fixed action pattern? Zeitschrift für Tierpsychologie, 36, 184-211.

SeEman, P. (1980). Dopamine receptors. Pharmacological Reviews, 32, 229-313.

Segal, M., \& BLoom, F. E. (1974). The action of norepinephrine in the rat hippocampus: II. Activation of the input pathway. Brain Research, 72, 99-114.

SHEFFIELD, F. D., \& ROBY, T. B. (1950). Reward value of a nonnutritive sweet taste. Journal of Comparative \& Physiological Psychology, 43, 471-481.

SHERRINGTON, C. S. (1906). The integrative action of the nervous system. New Haven: Yale University Press.

SkINNER, B. F. (1953). Science and human behavior. New York: Macmillan.

SmIrH, D. A. (1972). Increased perioral responsiveness: A possible explanation for the switching of behavior observed during lateral hypothalamic stimulation. Physiology \& Behavior, 8, 1077-1086.
Stricker, E. M., \& Zigmond, M. J. (1974). Effects on homeostasis of intraventricular injections of 6-hydroxydopamine in rats. Journal of Comparative \& Physiological Psychology, 86, 973-994.

SwaNson, L. W. (1977). Immunohistochemical evidence for a neurophysin-containing autonomic pathway arising in the paraventricular nucleus of the hypothalamus. Brain Research, 128, 346-353.

Tennyson, V. M., Heikkila, R., Mytilineou, C., Cote, L., \& CoHEN, G. (1974). 5-hydroxydopamine 'tagged' neuronal boutons in rabbit neostriatum: Interrelationship between vesicles and axonal membrane. Brain Research, 82, 341-348.

Tinbergen, N. (1951). The study of instinct. Oxford: Clarendon Press.

ToATEs, F. M. (1979). Homeostasis and drinking. Behavioral \& Brain Sciences, 2, 95-139.

Toates, F. M. (1981). The control of ingestive behavior by internal and external stimuli-A theoretical review. Appetite, 2, 35-50.

Troland, L. T. (1928). The fundamentals of human motivation. New York: Van Nostrand.

VANDERWOLF, C. H., \& RoBinson, T. E. (1981). Reticulo-cortical activity and behavior: A critique of the arousal theory and a new synthesis. Behavioral \& Brain Sciences, 4, 459-514.

VON Euler, U. S. (1946). A specific sympathomimetic ergone in adrenergic nerve fibers (sympathin) and its relation to adrenaline and noradrenaline. Acta Physiologica Scandinavica, 12, 73-97.

WARREN, R. P., \& HiNDE, R. A. (1959). The effect of oestrogen and progesterone on the nest-building of domestic canaries. Animal Behaviour, 7, 209-213.

Wasman, M., \& FlYNN, J. P. (1962). Directed attack elicited from hypothalamus. Archives of Neurology (Chicago), 6, 220-227.

Waterhouse, B. D., Moises, H. C., \& WoodWard, D. J. (1980). Noradrenergic modulation of somatosensory cortical neuronal responses to iontophoretically applied putative neurotransmitters. $E \boldsymbol{x}$ perimental Neurology, 69, 30-49.

WERMAN, R. (1966). Criteria for identification of a central nervous system transmitter. Comparative Biochemical Physiology, 18, 45-66.

WIKLER, A. (1952). A psychodynamic study of a patient during selfregulated readdiction to morphine. Psychiatric Quarterly, 26, $270-293$.

Wise, R. A. (1974). Lateral hypothalamic electrical stimulation: Does it make animals hungry? Brain Research, 67, 187-209.

Wise, R. A. (1978). Catecholamine theories of reward: A critical review. Brain Research, 152, 215-247.

WiSE, R. A. (1982). Neuroleptics and operant behavior: The anhedonia hypothesis. Behavioral \& Brain Sciences, 5, 39-87.

WiSE, R. A., \& Raptis, L. (1985). Effects of pre-feeding on foodapproach latency and food consumption speed in food deprived rats. Physiology \& Behavior, 35, 961-963.

WOODWORTH, R. S. (1958). Dynamics of behavior. New York: Holt. ZIEGLGANSBERGER, W. (1984). Opioid actions on mammalian spinal neurons. International Review of Neurobiology, 25, 243-275.

(Manuscript received June 9, 1986; revision accepted for publication January 4, 1987.) 